\title{
Contribuição da dieta e água alcalina na redução de complicações da doença renal crônica
}

\section{Contribution of alkaline diet and water in reducing complications of chronic renal disease}

\begin{abstract}
Aline Souza Carneiro da Silva', Eliane Moreira Vaz²
'Nutricionista, Especialização em Nutrição Clínica, Instituto de Nutrição Josué de Castro, da Universidade Federal do Ŗio de Janeiro

${ }^{2}$ Nutricionista, Doutora em Nutrição, Professora aposentada do Instituto de Nutrição Josué de Castro, da Universidade Federal do Rio de Janeiro
\end{abstract}

Contato: Eliane Moreira Vaz - elianemvaz@terra.com.br

\section{Resumo}

Atualmente, a terapia nutricional alcalina tem suscitado grande discussão no meio científico, como fator de proteção renal. Com o objetivo de determinar o nível de evidência científica dos trabalhos publicados sobre a influência da dieta e água alcalina na redução de complicações na doença renal crônica, foi realizada revisão de literatura em seis bases de dados: Biblioteca Virtual em Saúde (BVS) da BIREME, PubMed, Web of Science (WoS), SCOPUS e Cochrane Library, utilizando as seguintes palavras-chave: água alcalina, doença renal crônica, dieta alcalina, frutas, verduras, taxa de filtração glomerular, carga potencial de ácido renal. Foram encontradas 1071 referências. Excluindo as duplicatas e selecionando os estudos que tratassem especificamente a temática, totalizaram 34 artigos. Após a seleção dos artigos e classificação quanto ao tipo de estudo foi determinado o nível de evidência científica dos artigos, segundo Hood. Os estudos selecionados por esta revisão consideram que as dietas alcalinas a base de frutas e verduras e a administração de bicarbonato podem interferir nas complicações da Doença Renal Crônica, como redução da acidose metabólica e manutenção da taxa de filtração glomerular, sem ter sido possível encontrar o papel da água mineral alcalina nesse desfecho. Entretanto, apenas $27 \%$ dos estudos apresentaram evidência científica superior a cinco, em uma escala de um a dez, em que dez apresenta maior evidência científica e um a menor. Esses dados nos remetem a necessidade de mais estudos com melhores desenhos, maiores casuísticas, sem vieses e conflitos de interesse.

Palavras-chave: Água alcalina. Doença renal crônica. Dieta alcalina. Frutas. Verduras. Taxa de filtração glomerular. Carga potencial de ácido renal.

\begin{abstract}
Currently, alkaline nutritional therapy has raised great discussion in the scientific environment as a factor of renal protection. In order to determine the level of scientific evidence on the influence of diet and alkaline water on the reduction of complications in chronic kidney disease, a review of literature was carried out in six databases: BIREME Virtual Health Library (BVS), PubMed, Web of Science (WOS), SCOPUS and Cochrane Library, using the following keywords: alkaline
\end{abstract}


water, chronic kidney disease / chronic kidney insufficiency, alkaline diet, fruit, vegetables, glomerular filtration rate, potential renal acid load. A total of 7071 references were found. Excluding the duplicates and selecting the articles that deal specifically with the theme, it had totalized 34 articles. After selecting the articles and classifying the type of study, the level of scientific evidence of the articles was determined according to Hood. The studies selected by this review consider that alkaline diets based on fruits and vegetables and the administration of bicarbonate can interfere in the complications of Chronic Renal Disease, such as reducing metabolic acidosis and maintaining the glomerular filtration rate, without being able to find the role of alkaline mineral water in this outcome. However, only $27 \%$ of the studies presented more than five scientific evidence, on a scale of one to ten, where ten has the highest scientific evidence and one the lowest. These data point us to the need for more studies with better designs, larger samples, without biases and conflicts of interest.

Keywords: Alkaline water, Chronic kidney disease. Alkaline diet. Fruit. Vegetables. Glomerular filtration rate. Potential renal acid load.

\section{INTRODUÇÃO}

A doença renal crônica (DRC) é um problema de saúde pública que indica alto custo e mortalidade. As principais causas vão desde as doenças primárias até as sistêmicas, com destaque para a nefropatia diabética, hipertensão e glomerulonefrite ${ }^{1}$.

A insuficiência renal é definida quando os rins são incapazes de remover os produtos de degradação metabólica do corpo ou de realizar as funções reguladoras. As substâncias que são normalmente eliminadas na urina acumulam-se nos fluídos corporais. O comprometimento da filtração glomerular e, consequentemente, da excreção renal, leva a uma falha nas funções endócrinas e metabólicas, bem como a distúrbios hidroeletrolíticos e ácido-base. A Insuficiência Renal Aguda (IRA) é reconhecida quando a alteração da filtração glomerular ocorre de forma abrupta, enquanto a Insuficiência Renal Crônica (IRC) é progressiva e geralmente irreversível².

Na Doença Renal Crônica (DRC) observa-se como uma complicação de intensidade moderada a grave a acidose metabólica, resultado da excreção renal de ácido. Ainda que a acidose metabólica de baixo grau, quadro caracterizado por alterações mínimas no valor de $\mathrm{pH}$ sanguíneo, dentro da faixa considerada normal, seja uma complicação tardia, a acidose metabólica subclínica apresenta-se desde o início e pode ser mascarada pelo tamponamento ósseo ${ }^{3-5}$.

Um dos fatores principais da fisiologia humana é preservar o equilíbrio ácido-base. A concentração de hidrogênio, refletida pelo $\mathrm{pH}$, é o principal determinante no controle da homeostase, destacando as reações enzimáticas ${ }^{6}$. 
Para a manutenção da estabilidade do meio interno deve haver equilíbrio entre a produção e a remoção de íons hidrogênio $(\mathrm{H}+)$ no organismo. Além dos rins, fundamentais na eliminação do $\mathrm{H}+$, outros órgãos estão relacionados ao balanço ácido-base, como o intestino, o fígado e os pulmões?

Estudos recentes sugerem que a acidose metabólica pode contribuir para a progressão da DRC e a alta carga de ácido dietético pode diminuir a função renal. As dietas com potencial alcalinizante, ricas em frutas e verduras, podem neutralizar a produção de ácidos, resultantes da ingestão de um excesso de alimentos acidificantes, como queijo, carne, ovos e grãos, característicos das dietas contemporâneas ${ }^{3}$.

Os mecanismos pelo qual a dieta ácida poderá deteriorar a função renal são explicados pela toxicidade tubular de amônia e ativação do sistema reninaangiotensina $^{8}$. A literatura atesta que o tratamento com álcalis dietético, como bicarbonato ou frutas e vegetais, melhora a taxa de filtração glomerular e reduz a atividade da angiotensina II 9 .

A água é considerada o líquido essencial à vida. $\mathrm{O}$ homem adulto é constituído por mais de $60 \%$ de água, o que determina a sua importância para a saúde. $O$ funcionamento do organismo depende fundamentalmente da água. Ademais de transportar os nutrientes pelos diferentes órgãos, a água ajuda a regular a temperatura, eliminar as toxinas, por meio da urina e transpiração, estimula o trânsito intestinal e participa de inúmeras reações enzimáticas, entre outras funções.

Atualmente, as águas minerais alcalinas, com teor significativo de magnésio, cálcio e bicarbonato, parecem apresentar efeitos benéficos, como a manutenção da saúde óssea, a preservação da massa corpórea magra e a redução do risco de doenças, tais como hipertensão, enxaqueca e Alzheimer ${ }^{10,11}$.

Diante do exposto e considerando as inúmeras dúvidas que surgem diante dos proponentes da saúde, o presente estudo tem como objetivo geral revisar na literatura, considerando o nível de evidência científica dos trabalhos publicados, a influência da dieta e água alcalina na redução de complicações na doença renal crônica e como objetivos específicos, analisar o efeito da ingestão de frutas e verduras na redução da acidose metabólica e melhora da taxa de filtração glomerular e verificar a relação da água e dieta alcalina e melhora da função renal. 


\section{MÉTODO}

O presente estudo trata de revisão de literatura narrativa sobre a participação da dieta e água alcalina na redução de complicações na doença renal crônica. Para delimitação da pesquisa bibliográfica foi realizada uma busca em seis bases de dados e encontrados um total de 1071 referências: Biblioteca Virtual em Saúde (BVS) da BIREME (7), PubMed (144), Web of Science (WoS) (161), SCOPUS (220) e Cochrane Library (539), utilizando as seguintes palavras-chave: alkaline water, chronic kidney disease, alkaline diet, fruit, vegetables, glomerular filtration rate, potential renal acid load. Verificou-se 231 duplicatas. Do total de 840, considerando o título, foram selecionados 70 artigos. Dos 70 artigos, 39 foram utilizados na presente revisão e 34 trataram especificamente da temática dieta e água alcalina e redução de complicações da Doença Renal Crônica.

Os critérios de inclusão foram: textos completos de livre acesso; publicados nos idiomas inglês, espanhol e português; artigos originais de pesquisa, revisão de literatura ou relatos de casos clínicos; que versaram sobre o tema dieta e água alcalina na redução de complicações da doença renal crônica, publicados entre os anos 2000 e 2018.

Os critérios de exclusão: Cartas ao Editor, Editoriais e os textos completos que não versassem sobre o tema, bem como os estudos publicados em periódicos de acesso controlado e publicações anteriores ao ano 2000, exceto estudos clássicos, como diretrizes e conceituais.

Após a seleção dos artigos e classificação quanto ao tipo de estudo foi determinado o nível de evidência científica dos artigos, segundo Hood (2003)

Para a identificação do nível de evidência (NE) dos artigos selecionados foi considerada a seguinte classificação adaptada, com dez (10) níveis hierárquicos, como descritos a seguir: Pontos/Tipo de estudo - 10 - Maior Evidência: Revisões Sistemáticas com meta-análise de ensaios clínicos randomizados; 9 - Revisões sistemáticas com meta-análise; 8 - Ensaios Clínicos Randomizados; 7 - Guias de Prática Clínica; 6 - Estudos de Coorte e de Caso-Controle; 5 - Estudos Observacionais (longitudinais ou transversais); 4 - Casos Clínicos e Série de Casos; 3 - Pesquisa Básica Laboratorial; 2 - Opiniões de Especialistas; 1 - Menor Evidência: Revisões não sistemáticas da literatura ${ }^{12}$.

A análise dos dados foi descritiva. 


\section{DOENÇA RENAL CRÔNICA (DRC)}

A DRC tem sido considerada um importante problema de saúde pública mundial em decorrência do expressivo aumento das taxas de incidência e prevalência'

As principais alterações na insuficiência renal são aquelas relacionadas com a dificuldade de remover os produtos do metabolismo do corpo ou mesmo as alterações nas funções reguladoras. $O$ acúmulo de substâncias que normalmente são eliminadas pela urina promove falha nas funções endócrinas e metabólicas, bem como distúrbios hidroeletrolíticos e ácido-base. A insuficiência renal é uma doença sistêmica e consiste na via final comum de diferentes doenças do rim e do trato urinário. A DRC refere-se a um diagnóstico sindrômico de perda progressiva e geralmente irreversível da função renal de depuração, ou seja, da filtração glomerular ${ }^{2}$.

Em um estudo descritivo epidemiológico, com 217 pacientes que realizavam diálise, a pelo menos três anos, verificou que as principais causas da DRC foram: nefroesclerose hipertensiva, diabetes, glomerulonefrite e que as doenças associadas foram Hipertensão Arterial Sistêmica e Diabetes Mellitus².

Em 2002, a Kidney Disease Outcome Quality Initiative (KDOQI) ${ }^{13}$, publicou uma diretriz sobre DRC que compreendia avaliação, classificação e estratificação de risco. Nesse documento, uma nova estrutura conceitual para o diagnóstico de DRC foi proposta e aceita mundialmente. A definição é baseada em três componentes: (1) um componente anatômico ou estrutural (marcadores de dano renal); (2) um componente funcional (baseado na Taxa de Filtração Glomerular - TFG) e (3) um componente temporal. Com base nessa definição, seria portador de DRC qualquer indivíduo que, independente da causa, apresentasse $\mathrm{TFG}<60 \mathrm{~mL} / \mathrm{min} / 1,73 \mathrm{~m}^{2}$ ou a $\mathrm{TFG}>60 \mathrm{~mL} / \mathrm{min} / 1,73 \mathrm{~m}^{2}$, associada a pelo menos um marcador de dano renal parenquimatoso (por exemplo, proteinúria), presente há pelo menos três (3) meses. A KDOQI sugeriu que a DRC deveria ser classificada em estágios baseados na TFG, proteinúria (ou albuminúria) e também na apresentação do marcador de dano renal, já que é mais frequentemente utilizada com essa finalidade. Entretanto, outros marcadores de dano renal também podem ser empregados, tais como outras alterações na urina (por exemplo, hematúria glomerular), imagens ultrassonográficas anormais (por exemplo, presença de cistos na doença renal policística do adulto) ou alterações histopatológicas vistas em biópsias renais (por exemplo, alterações glomerulares com ou sem envolvimento do túbulo intersticial $)^{14}$. 


\section{EQUILIBRIO ÁCIDO-BASE}

Os fundamentos e conceitos do metabolismo de ácidos e bases são essenciais para entender os mecanismos que podem provocar alterações nesse equilíbrio.

Ácido é todo composto capaz de doar ions $\mathrm{H}+$, enquanto que bases são compostos capazes de receber esses íons. É fundamental que o organismo controle a concentração de ions $\mathrm{H}+$ para preservar o funcionamento adequado. A concentração de hidrogênio, refletida pelo $\mathrm{pH}$, é o principal determinante no controle da homeostase, destacando as reações enzimáticas. Este pH deverá ser mantido entre 7,35 (sangue venoso) a 7,45 (sangue arterial) e qualquer mudança nesses valores é rapidamente controlada pelo sistema tampão do organismo ${ }^{6,15}$.

Os sistemas orgânicos apresentam dois obstáculos para a manutenção do equilíbrio ácido-base (EAB). O primeiro é a quantidade de ácidos ingeridos na dieta diária. $\mathrm{O}$ segundo é a rota dada ao dióxido de carbono $\left(\mathrm{CO}_{2}\right)$ gerado como produto final do metabolismo. Para manter o $\mathrm{pH}$ em limites compatíveis com os processos vitais, o organismo lança mão de uma série de mecanismos bioquímicos como, regulação respiratória e regulação do sistema renal, com destaque para o sistema tampão. $\mathrm{O}$ sistema tampão do organismo apresenta quatro grandes componentes: bicarbonato; ácido carbônico, proteínatos; proteínas, fosfatos monoácidos; fosfatos biácidos e hemoglobinato; hemoglobina, estes são responsáveis por manter o pH em equilíbrio em razão da adição ou subtração de íons H+. Entre os tampões do espaço extracelular, o bicarbonato e as proteínas plasmáticas desempenham um papel de grande relevância, enquanto a hemoglobina e os fosfatos estão em primeiro plano no compartimento intracelular. Os sistemas de tamponamento minimizam modificações significativas da concentração dos íons $\mathrm{H}+$ livres ou do pH. O tampão bicarbonato é o mais destacado ${ }^{16}$.

O organismo constantemente produz ácidos não voláteis derivados dos próprios processos metabólicos, sendo a principal origem desses ácidos o metabolismo das proteínas, formadas por aminoácidos contendo enxofre (metionina e cisteína), os quais levam a formação de ácido sulfúrico ${ }^{17}$.

O intestino está diretamente envolvido no equilíbrio ácido-base, devido ao seu papel na absorção de ácidos e bases derivados dos alimentos e por conduzir ânions orgânicos e aminoácidos sulfurados para serem oxidados no fígado ${ }^{18}$. 


\section{PAPEL DOS RINS NO EQUILÍBRIO ÁCIDO-BASE}

Junto aos pulmões, os rins são responsáveis pela manutenção do pH do líquido extracelular dentro de valores muito estreitos, corroborando para homeostase do corpo humano ${ }^{16,19,20}$.

Os rins agem de forma mais lenta em relação ao sistema tampão e aos mecanismos respiratórios, entretanto, diferem por sua capacidade de continuar funcionando durante horas ou dias até alcançar o valor normal do pH. Portanto, a principal participação do mecanismo renal na regulação da concentração de íons H+ não é a rapidez de sua ação e sim, a capacidade de neutralizar por completo qualquer excesso de ácido ou de álcali que penetre nos líquidos corporais. Por outro lado, essa regulação é afetada quando persiste o excesso de ácido ${ }^{21}$.

O rim promove a regulação da única saída de hidrogênio em várias circunstâncias. A secreção de hidrogênio para o líquido tubular ocorre nas células epiteliais dos túbulos proximal e distal, do seguimento espesso do ramo ascendente da alça de Henle, dos túbulos coletores e dos canais coletores renais. O processo secretório começa com $\mathrm{CO}_{2}$ que se difunde para dentro das células ou é formado pelo metabolismo das células epiteliais tubulares. Sob influência da enzima anidrase carbônica, combina-se com a água para formar ácido carbônico que se dissocia em um íon hidrogênio e um íon bicarbonato. Esse íon hidrogênio, por mecanismo de contra-transporte, é secretado para o líquido tubular, por meio da troca de íon de sódio $(\mathrm{Na}+)$. O sódio do líquido tubular, inicialmente, combina-se com uma proteína carreadora na borda luminal da membrana celular e ao mesmo tempo um íon hidrogênio dentro da célula combina-se com o lado oposto da mesma proteína carreadora, por diferenças de gradiente de concentração de sódio dentro da célula e no líquido tubular, o sódio entra para o interior da célula, o hidrogênio sai para o lúmen tubular. A secreção de íon hidrogênio pode continuar até que o pH do líquido luminal, reduza para $4,5^{21}$.

A reabsorção de bicarbonato não acontece diretamente pelos túbulos, ela é iniciada por uma reação entre o íon bicarbonato e o íon hidrogênio, secretada pelas células tubulares, formando ácido carbônico que irá dissociar-se em água e CO2. Em seguida, o dióxido de carbono irá difundir-se para dentro da célula epitelial onde irá reagir com a água, através da anidrase carbônica, formando ácido carbônico que, novamente, irá se dissociar formando íon hidrogênio e íon bicarbonato. A seguir, esse íon bicarbonato difunde-se para o líquido extracelular em combinação com um 
íon sódio que foi absorvido do túbulo. As reações químicas responsáveis pela formação de íon hidrogênio nas células epiteliais ocorrem de forma que, cada vez que um íon hidrogênio é formado ocorre a formação de um íon bicarbonato, pela dissociação de ácido carbônico em hidrogênio e bicarbonato. Para que o H+ saia é necessário a presença de bicarbonato de sódio no filtrado glomerular que irá dissociar-se, permitindo a troca direta via contra-transporte de íon hidrogênio intracelular por íon sódio do líquido luminal. Para cada íon hidrogênio secretado para o líquido luminal, ocorre reabsorção indireta de íon bicarbonato ${ }^{21}$.

\section{ACIDOSE METABÓLICA NA DOENÇA RENAL CRÔNICA}

Acidose metabólica é uma complicação comum na DRC e resulta da geração de ácidos e da capacidade comprometida dos rins de excretar ácido e amônia, indicando possível gravidade da acidose nesse grupo de enfermos. Embora acidose metabólica de baixo grau seja uma complicação tardia na DRC, a acidose metabólica subclínica começa no início de a DRC e pode ser mascarada pelo tamponamento ósseo ${ }^{3,5}$. Atualmente, a literatura sugere que os padrões modernos de ingestão dietética resultam em acidose metabólica de baixo grau e subclínica em pacientes portadores de $\mathrm{DRC}^{3,8}$.

A retenção de ácido nos tecidos acelera a progressão da DRC, devido ao aumento dos níveis renais de angiotensina, angiotensina II, aldosterona e amoniogênese, piorando a fibrose ${ }^{8}$.

Alguns estudos observacionais demonstraram que a acidose metabólica está associada à progressão da doença renal ${ }^{22,23}$ e o aparecimento de várias complicações, entre elas a redução da massa magra ${ }^{18}$. Em concordância com esses achados, um estudo randomizado controlado em um único centro, demonstrou que a melhora da acidose metabólica retardou a progressão da DRC com a suplementação oral de bicarbonato nos pacientes em fase de pré-diálise. ${ }^{9}$ Atualmente, a terapia alcalina, como o uso de bicarbonato e a dieta com muito baixo teor proteico, têm suscitado grande discussão no meio científico como fator de proteção renal ${ }^{14,24,25}$.

\section{DIETA E ÁGUA ALCALINA NA REDUÇÃo dE COMPLICAÇÕES DA DOENÇA RENAL CRÔNICA}

O tipo de dieta poderá fornecer precursores ácidos ou básicos. A dieta ocidental contemporânea é caracterizada por alto conteúdo de produtos animais, que fornece alta carga ácida não volátil. A redução da ingestão desses alimentos, com elevada 
carga ácida, implicará no controle da acidose metabólica de baixo grau, preservando ossos e músculos e retardando o declínio da taxa de filtração glomerular15,18,26,27.

Os fatores de risco dietéticos que contribuem para a carga ácida são o sulfato e o fósforo (derivados do metabolismo proteico), enquanto que o fator dietético que contribui para a carga alcalina é o bicarbonato (e seus precursores), usualmente em associação com os minerais: potássio, magnésio e cálcio que podem ser encontrados nas águas minerais ${ }^{28}$.

O potencial de carga ácida dos alimentos - PRAL (Potential Renal Acid Load) foi estimada por Remer \& Manz (1995) ${ }^{29}$ que consideraram para o cálculo as diferentes taxas de absorção intestinal dos nutrientes, balanço iônico para cálcio e magnésio e dissociação de fosfato a pH 7,4. Quanto mais negativo o valor de PRAL maior o potencial alcalinizante do alimento. O que define se um alimento ou bebida é alcalinizante ou acidificante não é o valor do pH e sim o valor de PRAL. ${ }^{15}$ Além do PRAL, Frassetto e colaboradores $(1998)^{30}$, propuseram o cálculo de produção líquida de ácido endógeno (net endogenous acid production - NEAP) em que destaca como principais componentes para a produção endógena de ácidos à proteína total e a quantidade de potássio. NEAP estimado (eNEAP) representa a carga alimentar total de ácido não volátil adicionado ao corpo e pode ser estimado indiretamente pela proporção de ingestão de proteína e potássio.

Goraya \& colaboradores (2012) $)^{31}$ verificaram que a administração por 30 dias de bicarbonato de sódio (0,5 mEq/kg/dia) foi comparável a ingestão ad libitum de frutas (maçã, damasco, laranja, pera, passas e morangos) e verduras (cenoura, couve-flor, berinjela, alface, batata, espinafre, tomate e abobrinha) na redução de ácido dietético, demonstrando o papel adjuvante à proteção renal. Os autores verificaram, ainda, maior redução da lesão renal em indivíduos em estágio 2 da DRC, em razão da nefropatia hipertensiva, do que no grupo em estágio 1. Destacaram, ainda, a necessidade de verificar, em longo prazo, esse efeito. Dando seguimento, esse mesmo grupo de pesquisadores ${ }^{32}$, observaram redução de ácido dietético com adição de bicarbonato ou adição de frutas e verduras à dieta base em pacientes com DRC, estágio 3, em um período de 36 meses, destacando a ação protetora renal. Em concordância, Yari \& colaboradores ${ }^{19}$, por meio de estudo de revisão, apresentaram evidências de que a redução do resíduo ácido por meio da dieta alcalina, a base de frutas e verduras, promove um efeito positivo na hemodinâmica renal, podendo constituir em uma terapia protetora renal. 
Di Iorio \& colaboradores (2017) $)^{33}$, destacaram que a terapia nutricional na DRC deverá considerar uma menor ingestão de proteínas, sódio, fósforo e alimentos ácidos, a fim de controlar a acidose metabólica e consideraram que as características da dieta devem ser hipercalórica (30 a 34Kcal/Kg) e hipoproteica $(0,3$ a 0,4g de proteína / Kg) e suplementada com aminoácidos e cetoácidos.

Scialla \& colaboradores (2011) ${ }^{24} \mathrm{em}$ um estudo randomizado multicêntrico, realizado com 462 afros americanos adultos, concluiu que reduzindo a produção de ácido endógeno, por meio da redução de proteínas na dieta e aumento da ingestão de frutas e legumes, pode elevar o bicarbonato e, consequentemente, é possível prevenir a acidose metabólica e a mortalidade em pacientes com DRC. Os resultados encontrados sugerem que modificações dietéticas são viáveis na prática clínica e podem minimizar a acidose metabólica na DRC. Entretanto, esse estudo apresenta limitação, uma vez que não utilizaram a pesagem para as medidas dietéticas.

A revisão realizada por Passey $^{8}$ destaca o papel dos rins para neutralizar o excesso de ácido dietético. Por outro lado, na DRC a capacidade para excretar ácido e amônia está prejudicada e que os mecanismos associados contribuem para o dano contínuo do rim. O equilíbrio entre os alimentos ácidos e alcalinos é fundamental para reduzir a carga ácida da dieta e, assim, tratar a DRC. Nessa mesma proposta, os estudos apresentados por Goraya \& Wesson ${ }^{34}$ afirmaram que, tanto em modelos animais, quanto em humanos, a redução da acidose metabólica com o consumo de frutas e verduras e a suplementação de bicarbonato parecem ter efeito protetor da função renal, retardando a redução da taxa de filtração glomerular. Entretanto, chamam a atenção de que a maioria dos estudos revisados, não sinaliza a hipercalemia, que poderá ser agravada pela ingestão desses alimentos.

Cupisti \& colaboradores ${ }^{35}$ em estudo avaliando os quatro tipos de dietas renais prescritas durante as consultas nutricionais, em que além de estimar valores de energia, proteína, carboidratos, lipídios, ácidos graxos insaturados e saturados, colesterol, cálcio, fósforo, magnésio, ferro, zinco, cobre, fibras, vitaminas A, C, B1, B2, B3, K1 e D, calcularam os valores de PRAL e NEAP, representando a carga ácida não volátil derivada da dieta produzida durante a digestão. Concluíram que as dietas renais vegetarianas e aquelas com muito baixa oferta proteica podem trazer benefícios para a microbiota intestinal e no equilíbrio ácido-base, sendo justificado pela presença de grandes quantidades de fibra e vitamina K1 e carga ácida muito baixa. 
Atualmente, a comunidade científica vem sinalizando a importância de aporte adequado de minerais, incluindo cálcio, magnésio, potássio e sódio no bom desenvolvimento e funcionamento do corpo humano. O magnésio desempenha inúmeras funções no organismo, como cofator em diversas reações enzimáticas do metabolismo intermediário, importante componente dos ossos e dentes, membrana celular, cromossomos, entre outras funções.

Carnauba \& colaboradores ${ }^{11}$ mostraram que uma baixa oferta de magnésio na dieta aumenta a probabilidade de ocorrência de doenças, tais como: Alzheimer, hipertensão, doenças coronarianas, diabetes tipo 2, acidente vascular cerebral (AVC) e enxaqueca. Por outro lado, é fundamental a atenção do cálcio, fósforo e potássio na DRC e dos fenômenos envolvidos na homeostase. Além disso, a ingestão de cloreto de sódio $(\mathrm{NaCl})$ é relatada como um preditor, independente da concentração plasmática de bicarbonato. Sendo assim, o $\mathrm{NaCl}$ pode exercer aproximadamente 50$100 \%$ do efeito produtor de acidose e, por isso, é considerado um preditor da acidose metabólica de baixo grau induzido pela dieta ${ }^{36}$.

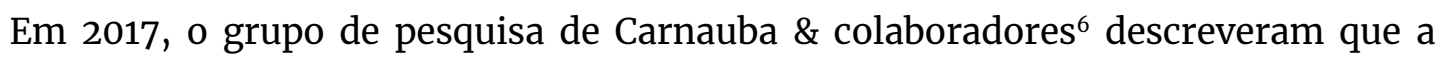
liberação de ácidos na corrente sanguínea promove várias alterações metabólicas, como a excreção mineral, resistência à insulina e estímulo a liberação de hormônio glicocorticoide e que tais desequilíbrios estão associados a um risco aumentado de doenças crônicas não transmissíveis, como a DRC.

As águas, de uma forma geral, sempre despertaram interesse seja em função da sua composição, como da sua qualidade microbiológica. Muitas doenças no passado foram erradicadas com simples procedimentos como ferver e filtrá-la. Atualmente, as águas minerais vêm sendo apresentadas como solução de muitos males e a indústria tem procurado explorar esse nicho comercial. Há estudos ${ }^{10,11,37}$ que ressaltam que as águas minerais naturais podem ser uma fonte essencial de cálcio, magnésio e outros minerais. Uma quantidade como $150 \mathrm{mg}$ de cálcio e $50 \mathrm{mg}$ de magnésio em um litro de água é reconhecida como significativa. Esses minerais, se apresentam na forma ionizada o que é melhor absorvido e a concentração desses minerais nas águas subterrâneas podem variar de acordo com as condições geológicas, composição mineral, ocorrência de gases no ambiente rochoso, especialmente, o dióxido de carbono e o teor geral de solução solúvel. Sabatier \& colaboradores $^{38}$ afirmaram que o magnésio é mais biodisponível, quando ingerido a partir de águas minerais. 
Frassetto \& colaboradores ${ }^{39}$ destacam um estudo controlado, randomizado, de quatro semanas, realizado em 30 mulheres jovens com uma ingestão de cálcio normal em que compararam o efeito nos marcadores ósseos de uma água mineral alcalina, rica em bicarbonato, com outra ácida, rica apenas em cálcio. A água ácida, rica em cálcio, não teve efeito sobre a reabsorção óssea, enquanto a água alcalina, rica em bicarbonato, apresentou uma significativa diminuição do hormônio paratiroidiano sérico e do marcador de reabsorção óssea C-telopéptido. Apesar de limitações da pesquisa, como o reduzido número amostral, os resultados foram concordantes com outros estudos que também encontraram diminuição da reabsorção óssea por meio da carga alcalina nutricional, ou pela água mineral rica em bicarbonato ou K-citrato.

Em 2015, um grupo de pesquisadores apresentou grande polêmica sobre o conceito de que alimentos com pH ácido apresentam ação acidificante no organismo, tendo como objeto a pesquisa de águas minerais obtidas de fontes situadas em terras brasileiras. Este estudo observou que o valor de $\mathrm{pH}$ não correlacionou com o valor de PRAL, não estando associado com o poder alcalinizante ou acidificante no organismo. Algumas águas minerais com valor de $\mathrm{pH}$ ácido apresentaram valores negativos de PRAL, exercendo, assim, potencial efeito alcalinizante. Esses dados corroboram, segundo os autores, para o fato de o valor do $\mathrm{pH}$ dos alimentos e bebidas não influenciar no equilíbrio ácido-base do organismo, pois não necessariamente reflete a capacidade de liberação de precursores de ácidos e bases ${ }^{15}$.

Por outro lado, empresas fabricantes de filtros, que tem por objetivo aumentar o potencial alcalinizante das águas minerais elevando o $\mathrm{pH}$, por meio da adição de magnésio, ressaltam que essas águas podem neutralizar a produção de ácido associado à ingestão de alimentos acidificantes, características das dietas ocidentais ${ }^{11}$.

\section{EVIDÊNCIA CIENTÍFICA DOS ARTIGOS UTILIZADOS NO PRESENTE ESTUDO, SEGUNDO HOOD ${ }^{12}$}

Dos 39 estudos utilizados nesta revisão, 34 foram avaliados quanto a evidência científica por estarem relacionados diretamente ao objeto da pesquisa. Dos 34 artigos, observou-se que seis (18\%) foram estudos randomizados e pontuados como oito (8) na escala de evidência científica, em que dez compreende maior evidência científica e um a menor. Três ( $9 \%$ ) dos artigos foram estudos de coorte, recebendo a pontuação seis (6); oito (23\%) dos artigos foram caracterizados como estudos observacionais longitudinais ou transversais e receberam pontuação cinco (5), 
apenas um (3\%) estudo compreendeu a pesquisa básica e 16 (47\%) foram artigos de revisão, ocupando a posição um (1) na escala, isto é, a de menor evidência científica. A maioria dos estudos (73\%) não ultrapassou evidência científica superior a cinco (5). O quadro 1 apresenta os artigos, segundo o tipo de estudo e evidência científica.

Quadro 1 - Relação dos artigos, segundo o tipo de estudo e evidência científica

\begin{tabular}{|llc|}
\hline Artigos & Tipo e Estudo'2 & $\begin{array}{c}\text { Evidência } \\
\text { Científica }\end{array}$ \\
\hline- & $\begin{array}{l}\text { Revisões sistemáticas com meta-análise de ensaios } \\
\text { clínicos randomizados }\end{array}$ & 10 \\
- & Revisões sistemáticas com meta-análise & 9 \\
$9,24,26,27,32,37$ & Ensaios clínicos randomizados & 8 \\
- & Guias de prática clínica & 7 \\
$22,23,33$ & Estudos de coorte e de caso-controle & 6 \\
$4,11,15,28,30,31,35,38$ & Estudos observacionais (longitudinais ou transversais) & 5 \\
- & Casos clínicos e série de casos & 4 \\
10 & Pesquisa básica laboratorial & 3 \\
- & Opiniões de especialistas & 2 \\
$3,5,6,7,8,10,16,17,18$, & Revisões não sistematizadas da literatura & 1 \\
$19,20,25,29,34,36,39$ & & \\
\hline
\end{tabular}

\section{CONCLUSÃO}

Os artigos identificados por este estudo consideram que as dietas alcalinas a base de frutas e verduras e a administração de bicarbonato podem interferir positivamente nas complicações da Doença Renal Crônica, sem ter sido possível encontrar o papel da água mineral alcalina nesse desfecho. Por outro lado, as pesquisas apresentam protocolos limitados, uma vez que os trabalhos experimentais não avaliam a abordagem da hipercalemia no grupo de pacientes com DRC, ingerindo quantidades significativas de frutas e verduras, em longo prazo. Os resultados desta revisão demonstraram que as evidências científicas dos artigos de livre acesso apresentaram, em sua maioria, nível igual ou inferior a cinco. Considerando os resultados apresentados, destaca-se a necessidade de mais estudos com melhores desenhos, casuísticas maiores, sem vieses e conflitos de interesse.

\section{COMENTÁRIOS FINAIS}

Os ensaios clínicos randomizados demandam custos elevados, o que podem limitar trabalhos de maior nível de evidência científica, incluídos neste estudo. Outro fator, possivelmente, restritivo a ser destacado é o fato das pesquisas de maior evidência científica serem encontradas em periódicos de acesso controlado, podendo justificar os resultados limitados da presente revisão. Logo, as informações obtidas podem auxiliar a tomada de decisão sobre a melhor dieta a ser indicada para indivíduos com 
DRC, necessitando proceder de maneira individualizada e monitoramento constante das alterações metabólicas e do estado nutricional.

\section{Agradecimento}

A Vanessa Mendonça, bibliotecária do Hospital Universitário Clementino Fraga Filho, da Universidade Federal do Rio de Janeiro, pela orientação e ajuda no levantamento bibliográfico.

\section{Conflito de interesse}

Os autores declaram não ter conflito de interesse.

\section{REFERÊNCIAS}

1. Lugon J R. Doença Renal Crônica no Brasil: um problema de saúde pública. J Bras Nefrol 2009; 31 (Supl 1): 2-5.

2. Ribeiro RCHM, Oliveira GASA, Ribeiro DF, Bertolin DC, Cesarino CB, Lima LCEQ Oliveira SM. Caracterização e etiologia da insuficiência renal crônica em uma unidade de nefrologia do interior do Estado de São Paulo. Acta Paul Enferm 2008;21: 207-11.

3. Scialla JJ, Anderson CAM. Dietary acid load: a novel nutritional target in chronic kidney disease? Adv Chronic Kidney Dis 2013; 20(2): 141-9.

4. Hsu C, Chertow GM. Elevations of serum phosphorus and potassium in mild to moderate chronic renal insufficiency. Nephrol Dial Transplant 2002; 17: 141925 .

5. Kraut JA, Kurtz I. Metabolic Acidosis of CKD: Diagnosis, clinical characteristics, and treatment. Am J Kidney Dis 2005; 45: 978-93.

6. Carnaúba RA, Baptistella AB, Paschoal V, Hübscher GH. Diet-induced low-grade metabolic acidosis and clinical outcomes: a review. Nutrients 2017; 9: 538-54.

7. Remer T. Influence of diet on acid-base balance. Seminars in Dialysis 2000; 13 (4): 221-6.

8. Passey C. Reducing the dietary dcid load: how a more alkaline diet benefits patients With Chronic Kidney Disease. Journal of Renal Nutrition 2017; 27(3):151-60.

9. Brito-Ashurst I, Varagunam M, Raftery MJ, Yaqoob MM. Bicarbonate supplementation slows progression of CKD and improves nutritional status. J Am Soc Nephrol 2009; 20: 2075-84.

10. Gątarska A, Tońska E, Ciborska J. Natural mineral bottled waters available on the polish market as a source of minerals for the consumers. Part 1. Calcium and magnesium. Rocz Panstw Zakl Hig 2016; 67(1): 1-8.

11. Carnauba RA, Moreton MS, Baptistella ABLF, Dantas NM, Santos NS, Naves A, et al. Agua alcalinizante y con alto contenido de magnesio: los posibles efectos beneficiosos para la salud. Actual nutr. 2015; 16(3): 83-9. 
12. Hood PD. Scientific Research and Evidence-Based Practice. San Francisco: WestEd 2003.51p.

13. Kidney Disease Outcome Quality Initiative - KDOQI clinical practice guidelines for chronic kidney disease: evaluation, classification and stratification. Am J Kidney Dis 2002; 39(Suppl 2): 1-246.

14. Bastos MG, Bregma R, Kirsztajn GM. Doença renal crônica: frequente e grave, mas também prevenível e tratável. Rev Assoc Com Bras 2010; 56(2): 248 -53.

15. Carnauba RA, Sussaio MM, Fonseca ABBL, Naves A, Paschoal V, Chaves DFS. Avaliação do potencial alcalinizante das águas minerais comercialmente disponíveis em território brasileiro. Nutrire Rev Soc Bras Aliment Nutr 2015; 40(3): 344-51.

16. Adamczak M, Masajtis-Zagajewska A, Mazanowska O, Madziarska K, Stompór $\mathrm{T}$, Więcek A. Diagnosis and treatment of metabolic acidosis in patients with chronic kidney disease - position statement of the working group of the Polish Society of Nephrology. Kidney Blood Press Res 2018; 43(3): 959-69.

17. Khairallah P, Scialla JJ. Role of acid-base homeostasis in diabetic kidney disease. Current Diabetes Reports 2017; 17(28): 1-11.

18. LEAL VO, JÚNIOR ML, MAFRA D. Acidose metabólica na doença renal crônica: abordagem nutricional. Rev Nutr Campinas 2008; 21(1): 93-103.

19. Yari Z, Mirmiran P. Alkaline diet a novel nutritional strategy in chronic kidney disease? Iranian Journal of Kidney Diseases 2018; 12(4):204-8.

20. Angéloco RN, Souza A, Romão A, Chiarello G. Alkaline diet and metabolic acidosis: practical approaches to the nutritional management of chronic kidney disease. Journal of Renal Nutrition 2018; 28(3): 215-20.

21. Piva JP, Garcia PCR, Martha VF. Distúrbios do equilíbrio ácido-básico. Jornal de Pediatria 1999; 75(Supl.2): 234-43.

22. Raphael KL, Wei G, Baird BC, Greene T, Beddhu S. Higher. Serum bicarbonate levels within the normal range are associated with better survival and renal outcomes in African Americans. Kidney Int 2010: 356-62.

23. Menon V, Tighiouart H, Vaughn NS, Beck GJ, Kusec jw, Collins AJ, et al. Serum bicarbonate and long-term outcomes in CKD. Am J Kidney Dis 2010: 56: 907-14.

24. Scialla JJ, Appel LJ, Astor BC, Miller ER, Beddhu S, Woodward M, et al. Estimated net endogenous acid production and serum bicarbonate in African Americans with chronic kidney disease. Clinical Journal of the American Society of Nephrology 2011; 6(7): 1526-32.

25. Siener R. Dietary treatment og metabolic acidosis in chronic kidney disease. Nutrients 2018 (10): 512-518, 31.

26. Buclin T, Cosma M, Appenzeller M, Jacquet AF, Décosterd LA, Biollaz J, Burckhardt P. Diet acids and alkalis influence calcium retention in bone. Osteoporos. Int. 2001: 12: 493-99.

27. Jehle S, Hulter HN, Krapf R. Effect of potassium citrate on bone density, microarchitecture, and fracture riskin healthy older adults without osteoporosis: A randomized controlled trial. J. Clin. Endocrinol. Metab 2013; 98 : 207-17. 
28. Wynn E, Raetz E, Burckhardt P. The composition of mineral waters sourced from Europe and North America in respect to bone health: composition of mineral water optimal for bone. British Journal of Nutrition 2009; 101(8): 1195-9.

29. Remer T, Manz F. Potential renal acid load of foods and it's influence on urine pH. J Am Diet Assoc 1995; 95: 791-97.

30. Frassetto LA, Todd MK, Júnior MCR, Sebastian A. Estimation of net endogenous noncarbonic acid production in humans from diet potassium and protein contents. J Clin Nutr 1998; 68: 576-83.

31. Goraya N, Simoni J, Jo C, Wesson DE. Dietary acid reduction with fruits and vegetables or bicarbonate attenuates kidney injury in patients with a moderately reduced glomerular filtration rate due to hypertensive nephropathy. Kidney International 2012; 81(1): 86-93.

32. Goraya N, Simoni J, Jo CH, Wesson DE. Treatment of metabolic acidosis in patients with stage 3 chronic kidney disease with fruits and vegetables or oral bicarbonate reduces urine angiotensinogen and preserves glomerular filtration rate. Kidney Int 2014; 86: 1031-8.

33. Di Iorio BR, Di Micco L, Marzocco S, De Simone E, De Blasio A, Sirico ML, et al. Very Low-Protein Diet (VLPD) Reduces metabolic acidosis in subjects with chronic kidney disease: The "nutritional light signal" of the renal acid load. Nutrients 2017; 9(1): 69-82.

34. Goraya N, Wesson DE. Does correction of metabolic acidosis slow chronic kidney disease progression? Curr Opin Nephrol Hypertens 2013; 22(2): 193-7.

35. Cupisti A, D'Alessandro C, Gesualdo L, Cosola C, Gallieni M, Egidi MF, et al. NonTraditional aspects of renal diets: focus on fiber, alkali and vitamin K1 intake. Nutrients 2017; 9(5): 444-59.

36. Telles C, Boitá ERF. Importância da terapia nutricional com ênfase no cálcio, fósforo, e potássio no tratamento da doença renal crônica. P.Erechim 2015: 39 (145): $143-54$.

37. Wynn E, Krieg MA, Aeschlimann JM, Burckhardt P. Alkaline mineral water lowers bone resorption even in calcium sufficiency: alkaline mineral water and bone metabolism. Bone 2009; 44(1): 120-4.

38. Sabatier M, Grandvuillemin A, Kastenmayer P, Aeschliman JM, Bouisset F, Arnaud MJ, et al. Influence of the consumption pattern of magnesium from magnesium-rich mineral water on magnesium bioavailability. British Journal of Nutrition 2011; 106: 331-34.

39. Frassetto L, Banerjee T, Powe N, Sebastian A. Acid balance, dietary acid load, and bone effects - A controversial subject. Nutrients 2018; 10: 517-25. 